\title{
Gastric Cancer: An Opportunity for Prevention
}

\author{
Cancro Gástrico: Uma Oportunidade para Prevenção
}

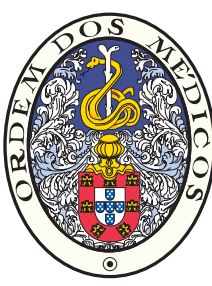

Miguel AREIA ${ }^{1,2}$, Pedro PIMENTEL-NUNES ${ }^{3,4}$, Ricardo MARCOS-PINTO $^{2,5}$, Mário DINIS-RIBEIRO 2,3 Acta Med Port 2013 Nov-Dec;26(6):627-629

Keywords: Endoscopy, Gastrointestinal; Helicobacter Infections; Helicobacter Pylori; Metaplasia; Stomach Neoplasms/prevention \& control.

Palavras-chave: Endoscopia Gastrointestinal; Helicobacter Pylori; Infecções por Helicobacter; Metaplasia; Neoplasias Gástricas/ prevenção e controlo.

Gastric cancer is one of the most prevalent cancers worldwide, ranking fourth after lung, breast and colorectal cancers, and it is the second cause of cancer death. The majority of cases occur in developing countries and are more common in males, irrespective of age and geographic area. In Portugal it ranks fifth in cancer deaths and its incidence is the highest in Western Europe.

The most common type of gastric cancer is adenocarcinoma, whose prevalence is related to male gender, increasing age and high prevalence regions, indicating environmental factors as risk factors for the disease. The accepted model for development of this type of cancer involves a cascade of premalignant conditions occurring over several years, due to environmental and host factors, which might progress to premalignant lesions (e.g. dysplasia) and invasive cancer.

Several observational studies have shown that environmental factors play a part and salt, nitrates, tobacco and Helicobacter pylori are the most fully described agents. Helicobacter pylori is the single main risk factor and considered to promote the development of these precursor conditions and lesions. The first of these may be gastric inflammation that progresses to loss of appropriate glands (atrophy), replacement of original glands with intestinal metaplasia glands that might develop into dysplasia and finally into invasive carcinoma. It is considered that their intragastric extension is also relevant in patients presenting with atrophy or intestinal metaplasia in the corpus, who represent a subgroup of higher risk patients for whom a specific surveillance programme is recommended.

Host factors, in particular genes that regulate expression of proinflammatory agents (interleukin $1 \beta$, tumournecrosis factor) and some innate immunity receptors such as toll-like receptors (TLRs) have been linked to gastric carcinogenesis but as yet without proven clinical implications.
Studies comparing the expression of TLRs and their inhibitors in all premalignant lesions of the gastric carcinogenesis cascade have provided a statistically significant trend for a decrease of TLR inhibitors and a progressive increase of TLR expression, in particular 0.1 for normal mucosa, 1.0 for gastritis, 2.2 for intestinal metaplasia and 2.8 for dysplasia $(p<0.001){ }^{1-4}$ Familial aggregation of gastric cancer might have some role in about $10 \%$ of cases, in particular in first relatives of early onset gastric cancer patients. In a casecontrol study these first degree relatives of gastric cancer patients presented an increased prevalence of Helicobacter pylori infection ( $82 \%$ versus $65 \%, p=0.001)$ and extensive atrophic gastritis or intestinal metaplasia (19\% versus $0 \%$, $p<0.001)$. These results are corroborated in the literature and seem to be independent of the source of controls used, reinforcing the recommendation for screening and treating for Helicobacter pylori in these cases and suggesting that a specific surveillance might be desirable, although this is still not consensual. ${ }^{5,6}$ Serologic measurement of pepsinogens I and II, normally produced in the gastric mucosa, could be used to screen for high-risk patients harbouring extensive premalignant conditions (e.g. detection of atrophy and/or intestinal metaplasia both in antrum and corpus). ${ }^{7}$ It was determined in several studies and in a recent meta-analysis that a pepsinogen I value $\leq 70$ and a pepsinogen I versus II ratio $\leq 3$ had a sensitivity of $77 \%$ and a negative predictive value of $99 \%$ for the diagnosis of dysplasia. ${ }^{8}$

For the endoscopic diagnosis of these premalignant lesions, conventional endoscopy does not present the required accuracy or reproducibility to preclude the need for taking biopsies: even in normal-appearing gastric mucosa, patients with a median pepsinogen $\mathrm{I} / \mathrm{II}$ ratio of 2.8 have intestinal metaplasia in both the antrum and corpus, and with a ratio of 1.8 more than $50 \%$ of the antrum will harbour intestinal metaplasia. ${ }^{9}$ Because of this lack of accuracy of

1. Gastroenterology Department. Portuguese Oncology Institute-Coimbra. Coimbra. Portugal.

2. CINTESIS - Center for Research in Health Technologies and Information Systems, Biostatistics and Medical Informatics. Faculty of Medicine. Porto University. Porto. Portugal.

3. Gastroenterology Department. Portuguese Oncology Institute-Porto. Porto. Portugal.

4. Department of Physiology. Cardiovascular Research and Development Unit. Faculty of Medicine. Porto University. Porto. Portugal.

5. Gastroenterology Department. Centro Hospitalar do Porto. University of Porto. Porto. Portugal.

Recebido: 10 de Julho de 2013 - Aceite: 20 de Julho de 2013 | Copyright @ Ordem dos Médicos 2013 
conventional endoscopy, a detailed endoscopic inspection should be backed up with biopsies. These should involve a minimum of two samples from the gastric antrum and two separate samples from the body, plus biopsies of any suspicious lesions identified. ${ }^{10}$

Recent endoscopic advances such as chromoendoscopy with methylene blue or narrow band imaging are better in terms of both diagnostic accuracy and reproducibility than conventional endoscopy and their use could be justified for the surveillance of a high risk population. ${ }^{11}$ Conventional chromoendoscopy with $1 \%$ methylene blue gave a diagnosis of dysplasia with a specificity of $81 \%(95 \%$ confidence interval $[\mathrm{Cl}]$ : $77-85 \%)$ and a negative predictive value of $99 \%(95 \% \mathrm{Cl}: 99-100 \%)$ along with a kappa statistic of 0.86 for intraobserver and 0.74 for interobserver agreements. ${ }^{12}$ These values were validated in another centre which provided very similar results for the diagnosis of dysplasia (sensitivity of $100 \%$, specificity of $99 \%$ ) and for reproducibility (kappa 0.92, 95\% Cl: 0.88-0.96) for classification in groups). ${ }^{13}$ Electronic chromoendoscopy by narrow band imaging for gastric precursor lesions has been evaluated in several studies, providing different classifications that were combined in a simplified classification. This was prospectively validated in a multicenter endoscopic study, providing diagnostic accuracies for normal mucosa of $83 \%$ (95\% Cl: $75-90 \%)$, intestinal metaplasia of $84 \%$ (95\% Cl: $77-91 \%)$ and dysplasia of $95 \%(95 \% \mathrm{Cl}: 90-99 \%)$. The global reproducibility was kappa $=0.62$ and varied between experienced versus non-experienced endoscopists $(0.75$ versus 0.60). ${ }^{14}$

Screening for gastric cancer is only cost-effective in high risk countries but in those countries, like Portugal, with an intermediate incidence of this disease, high-risk patients could be offered a specific surveillance programme. These high-risk patients present extensive atrophy or intestinal metaplasia involving the antrum and corpus, diagnosed by pepsinogen assessment or endoscopic biopsy as suggested in a recent consensus guideline. ${ }^{10}$ In these cases, endoscopic surveillance should be offered on a 3-yearly

\section{REFERENCES}

1. Pereira C, Sousa H, Ferreira P, Fragoso M, Moreira-Dias L, Lopes C, et al. $-765 G>C$ COX-2 polymorphism may be a susceptibility marker for gastric adenocarcinoma in patients with atrophy or intestinal metaplasia. World J Gastroenterol. 2006;12:5473-8.

2. Pimentel-Nunes $P$, Afonso L, Lopes $P$, Roncon-Albuquerque R Jr., Goncalves $\mathrm{N}$, Henrique $\mathrm{R}$, et al. Increased expression of toll-like receptors (TLR) 2, 4 and 5 in gastric dysplasia. Pathol Oncol Res. 2011;17:677-83.

3. Pimentel-Nunes P, Goncalves N, Boal-Carvalho I, Afonso L, Lopes P, Roncon-Albuquerque $\mathrm{R}$ Jr., et al. Helicobacter pylori induces increased expression of Toll-like receptors and decreased Toll-interacting protein in gastric mucosa that persists throughout gastric carcinogenesis. Helicobacter. 2013;18:22-32.

4. Pinto-Correia AL, Sousa H, Fragoso M, Moreira-Dias L, Lopes C, Medeiros R, et al. Gastric cancer in a Caucasian population: role of pepsinogen C genetic variants. World J Gastroenterol. 2006;12:5033-6.

5. Marcos-Pinto R, Carneiro F, Dinis-Ribeiro M, Wen X, Lopes C, Figueiredo $C$, et al. First-degree relatives of patients with early-onset gastric carcinoma show even at young ages a high prevalence of advanced OLGA OLGIM stages and dysplasia. Aliment Pharmacol Ther. 2012;35:1451-9.

6. Marcos-Pinto R, Dinis-Ribeiro M, Carneiro F, Machado JC, Figueiredo endoscopic schedule, supplemented with magnification chromoendoscopy or narrow-band imaging if available. If, whilst under surveillance, dysplasia is detected without a visible endoscopic lesion, close follow-up should be offered, either immediately in high grade cases or within 12 months for those with low grade. Patients with dysplasia or cancer within an endoscopically visible lesion should undergo staging and resection. ${ }^{10,15}$

This suggestion of surveillance of patients with premalignant conditions has only been evaluated by 3 cost-effectiveness studies and a recent review showed the results in the available literature to be contradictory (probably due to different assumptions on progression of precursor conditions). While the incremental cost-effectiveness ratio varied between 1868 and 72519 US dollars for intestinal metaplasia (crossing the usually accepted threshold of 50000 US dollars), for dysplasia incremental values ranged only between 18600 and 39800 US dollars. Although the evidence so far is slight, for dysplasia close follow-up seems to be the consensual approach for clinical and cost-effective purposes. ${ }^{16,17}$

In conclusion, gastric cancer is still a prevalent cancer worldwide and a health problem in several countries but different incident rates should lead to different attitudes. While in the Western world population screening is not cost-effective, screening for high-risk patients could lead to a better resource allocation and it could be done either by family history (especially in first relatives of early onset gastric cancer patients), serologic pepsinogen measurement or endoscopic evaluation with biopsies from the antrum and corpus.

For those patients harbouring a high-risk condition such as extensive atrophy or intestinal metaplasia in both the antrum and corpus, our attention and dedication should be unwavering and, although the results from cost-effectiveness studies are contradictory, our best endoscopic surveillance should be offered on a 3-yearly basis, alongside magnification chromoendoscopy or narrow-band imaging, if available.

$\mathrm{C}$, Reis CA, et al. First degree relatives and familial aggregation of gastric cancer: who to choose for control in case-control studies? Fam Cancer. 2012;11:137-43.

7. Lomba-Viana R, Dinis-Ribeiro M, Fonseca F, Vieira AS, Bento MJ, Lomba-Viana $\mathrm{H}$. Serum pepsinogen test for early detection of gastric cancer in a European country. Eur J Gastroenterol Hepatol. 2012;24:37-41.

8. Dinis-Ribeiro M, Yamaki G, Miki K, Costa-Pereira A, Matsukawa M, Kurihara M. Meta-analysis on the validity of pepsinogen test for gastric carcinoma, dysplasia or chronic atrophic gastritis screening. J Med Screen. 2004;11:141-7.

9. Areia M, Amaro P, Dinis-Ribeiro M, Moreira-Dias L, Romaozinho JM, Gouveia $\mathrm{H}$, et al. Estimation of the extent of gastric intestinal metaplasia by methylene blue chromoendoscopy. Eur J Gastroenterol Hepatol. 2008;20:939-40.

10. Dinis-Ribeiro $M$, Areia $M$, de Vries AC, Marcos-Pinto R, MonteiroSoares M, O'Connor A, et al. Management of precancerous conditions and lesions in the stomach (MAPS): guideline from the European Society of Gastrointestinal Endoscopy (ESGE), European Helicobacter Study Group (EHSG), European Society of Pathology (ESP), and the Sociedade Portuguesa de Endoscopia Digestiva (SPED). Endoscopy. 
2012;44:74-94.

11. Dinis-Ribeiro M. Chromoendoscopy for early diagnosis of gastric cancer. Eur J Gastroenterol Hepatol. 2006;18:831-8.

12. Dinis-Ribeiro M, da Costa-Pereira A, Lopes C, Lara-Santos L, Guilherme $M$, Moreira-Dias L, et al. Magnification chromoendoscopy for the diagnosis of gastric intestinal metaplasia and dysplasia. Gastrointest Endosc. 2003;57:498-504.

13. Areia M, Amaro P, Dinis-Ribeiro M, Cipriano MA, Marinho C, CostaPereira A, et al. External validation of a classification for methylene blue magnification chromoendoscopy in premalignant gastric lesions. Gastrointest Endosc. 2008;67:1011-8.

14. Pimentel-Nunes P, Dinis-Ribeiro M, Soares JB, Marcos-Pinto R, Santos $C$, Rolanda $C$, et al. A multicenter validation of an endoscopic classification with narrow band imaging for gastric precancerous and cancerous lesions. Endoscopy. 2012;44:236-46.

15. Ribeiro-Mourao F, Pimentel-Nunes P, Dinis-Ribeiro M. Endoscopic submucosal dissection for gastric lesions: results of an European inquiry. Endoscopy. 2010;42:814-9.

16. Areia M, Carvalho R, Cadime AT, Rocha Goncalves F, Dinis-Ribeiro M. Screening for Gastric Cancer and Surveillance of Premalignant Lesions: a Systematic Review of Cost-Effectiveness Studies. Helicobacter. 2013;18:325-37.

17. Dinis-Ribeiro M, da Costa-Pereira A, Lopes C, Moreira-Dias L. Feasibility and cost-effectiveness of using magnification chromoendoscopy and pepsinogen serum levels for the follow-up of patients with atrophic chronic gastritis and intestinal metaplasia. J Gastroenterol Hepatol. 2007;22:1594-604. 


\section{abbvie}

VAMOS REESCREVER

A HISTÓRIA DA HEPATITE C

A AbbVie está empenhada em criar impacto na vida das pessoas com Hepatite $C$

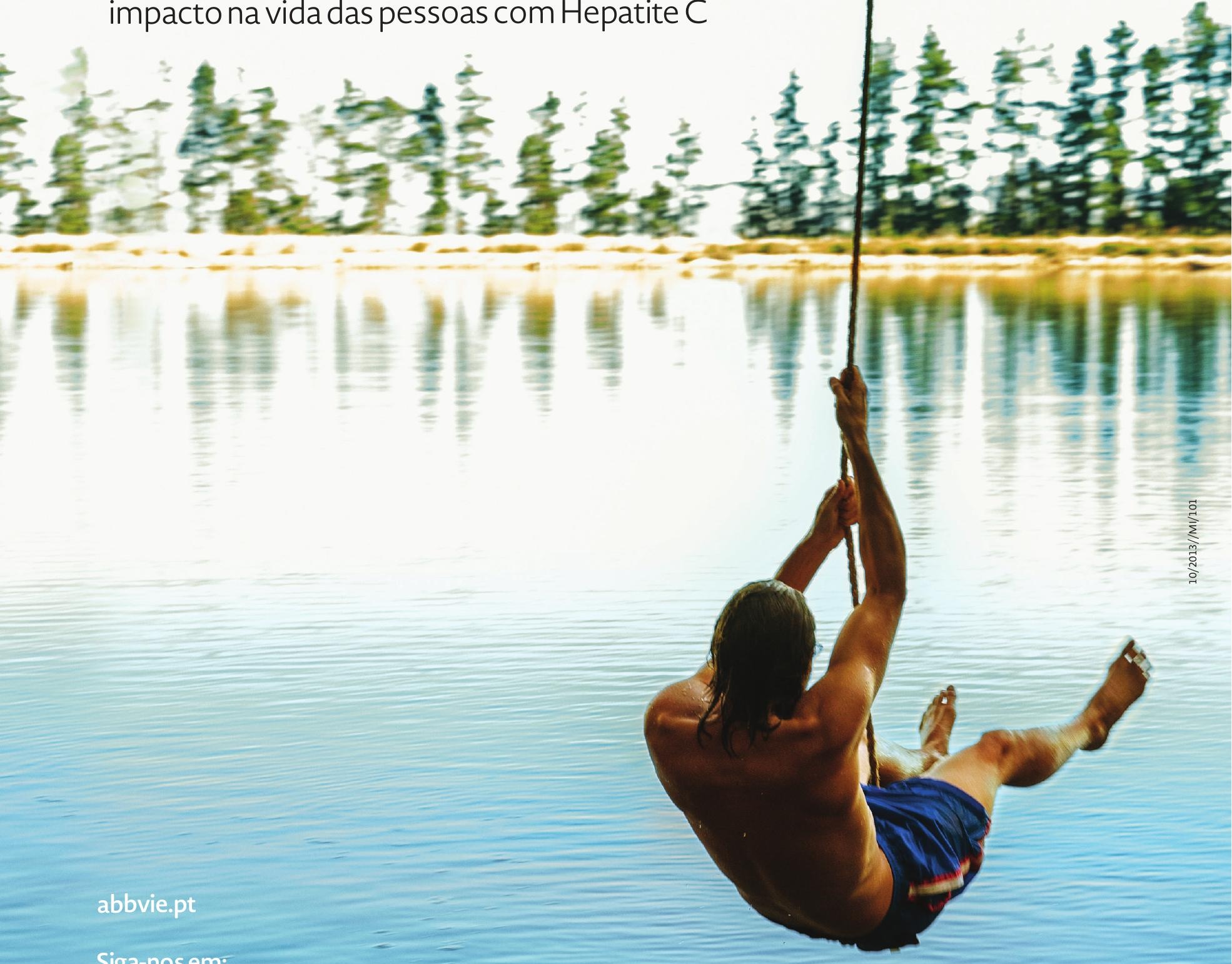

Siga-nos em:

\section{$f$ in $B$}

AbbVie, Lda.

Estrada de Alfragide, 67 Alfrapark-Edifício D|2610-008 Amadora

Telf. 211908400 | Fax. 211908403

Contribuinte e Matrícula na Conservatória do Reg. Com. da Amadora

n. ${ }^{\circ} 510229050 \mid$ Capital Social 4.000.000€ 


\section{Gastric Cancer: An Opportunity for Prevention Acta Med Port 2013:26:627-629}

Publicado pela Acta Médica Portuguesa, a Revista Científica da Ordem dos Médicos

Av. Almirante Gago Coutinho, 151

1749-084 Lisboa, Portugal.

Tel: +351218428215

E-mail: submissao@actamedicaportuguesa.com

www.actamedicaportuguesa.com

ISSN:0870-399X | e-ISSN: 1646-0758

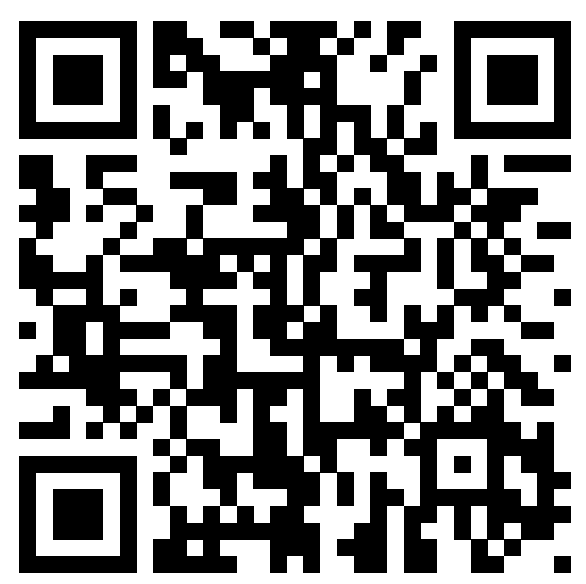

